NASA

Technical Memorandum 107147
Army Research Laboratory

Technical Report ARL-TR-957

\title{
Gear Crack Propagation Investigations
}

David G. Lewicki

Vehicle Propulsion Directorate

U.S. Army Research Laboratory

Lewis Research Center

Cleveland, Ohio

and

Roberto Ballarini

Case Western Reserve University.

Cleveland, Ohio

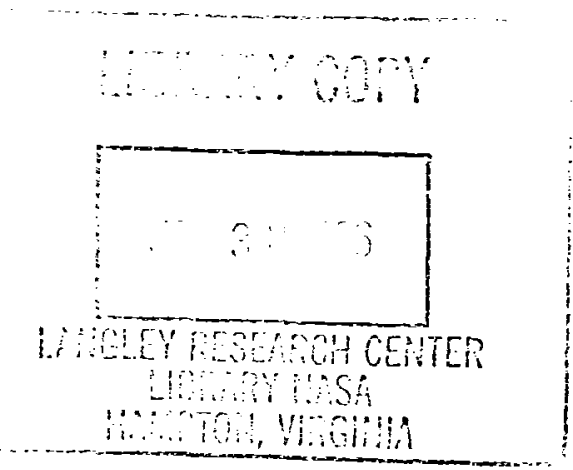

Prepared for

An Integrated Monitoring, Diagnostics, \& Failure Prevention

Technology Showcase

sponsored by the Society for Machinery Failure Prevention Technology

Mobile, Alabama, April 22-26, 1996

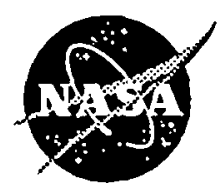

National Aeronautics and

Space Administration

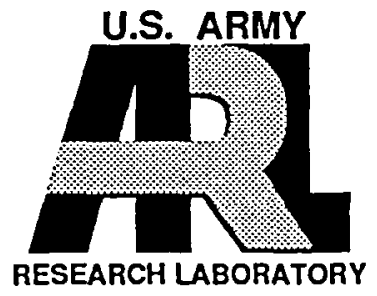


.

$+$ 


\title{
GEAR CRACK PROPAGATION INVESTIGATIONS
}

\author{
David G. Lewicki \\ Vehicle Propulsion Directorate \\ U.S. Army Research Laboratory \\ NASA Lewis Research Center \\ Cleveland, Ohio 44135 \\ Roberto Ballarini \\ Department of Civil Engineering and \\ Mechanical \& Aerospace Engineering \\ Case Western Reserve University \\ Cleveland, Ohio 44106
}

\begin{abstract}
Analytical and experimental studies were performed to investigate the effect of gear rim thickness on crack propagation life. The FRANC (FRacture ANalysis Code) computer program was used to simulate crack propagation. The FRANC program used principles of linear elastic fracture mechanics, finite element modeling, and a unique re-meshing scheme to determine crack tip stress distributions, estimate stress intensity factors, and model crack propagation. Various fatigue crack growth models were used to estimate crack propagation life based on the calculated stress intensity factors. Experimental tests were performed in a gear fatigue rig to validate predicted crack propagation results. Test gears were installed with special crack propagation gages in the tooth fillet region to measure bending fatigue crack growth. Good correlation between predicted and measured crack growth was achieved when the fatigue crack closure concept was introduced into the analysis. As the gear rim thickness decreased, the compressive cyclic stress in the gear tooth fillet region increased. This retarded crack growth and increased the number of crack propagation cycles to failure.
\end{abstract}

Key Words: Crack propagation; finite element modeling; fracture mechanics; gears; rims.

Introduction: A common design goal for gears in helicopter or turboprop power transmissions is reduced weight. To help meet this goal, some gear designs use thin rims. Rims that are too thin, however, may lead to bending fatigue problems and cracks. The most common methods of gear design and analysis are based on standards published by the American Gear Manufacturers Association. Included in the standards are rating formulas for gear tooth bending to prevent crack initiation [1]. These standards can include the effect of rim thickness on tooth bending fatigue [2]. The standards, however, do not give any indication of the crack propagation path or the remaining life once a crack has started. Fracture mechanics has developed into a useful discipline for predicting strength and life of cracked structures.

Ahmad and Loo [3] applied fracture mechanics to gear teeth to illustrate the procedure and estimate crack propagation direction. Honda and Conway [4] also applied fracture mechanics to simulate tooth crack propagation, compute threshold loads, and calculate tooth life. Flasker and Jezernik [5] applied fracture mechanics to gear teeth to estimate stress intensity factors and gear life. Researchers at Tohoku University in Japan performed a series of analyses and experiments to determine the effect of residual stress on crack initiation and propagation [6,7]. Also, Daniewicz, et al. [8] developed a comprehensive, self-contained analysis package to refine the spur gear 
bending fatigue theory using fracture mechanics. Lastly, Flasker and Pehan [9] described their method for calculating crack propagation in gear teeth using fracture mechanics. Much of the work of the above references considered only an initial crack and propagation paths were not considered. Many of the references that did consider crack propagation assumed the propagation occurred in a straight path. In addition, experimental validation of the cited analyses was sparse. Finally, no work using fracture mechanics was performed for thin-rim gears.

The objective of this study was to determine the effect of gear rim thickness on crack propagation life. From an extensive study [10], linear elastic fracture mechanics was used to analyze gear tooth bending fatigue in standard and thin-rim gears. Finite element computer programs were used to determine stress distributions, estimate stress intensity factors, and model crack propagation. Various fatigue crack growth models were used to estimate crack propagation life. Experimental tests were performed to validate predicted crack propagation results.

Fatigue Crack Growth: Many machine elements, such as gear teeth, are cyclicly loaded in application. The overall fatigue life of such components may be represented by three distinct phases: 1) crack initiation, 2) crack propagation, and 3) final failure. Once crack initiation has occurred, fracture mechanics may be used to estimate crack propagation fatigue growth rate and time to final failure.

The most universally used method to calculate crack propagation fatigue crack growth was postulated by Paris and Erdogan [11]. Considered were purely mode I loaded specimens subjected to cyclic load. Further considered was unstable crack growth such that the stress intensity factor grew with increasing crack size. Paris postulated that the rate of crack growth with respect to number of stress cycles was a logarithmic relationship with the stress intensity factor range as

$$
\frac{d a}{d N}=C(\Delta K)^{n}
$$

where $d a$ is the change in crack length for $d N$ number of stress cycles, $\Delta K$ is the range of the mode I stress intensity factor at a given time, and $C$ and $n$ are material constants. The material constants, $C$ and $n$, must be determined by some experimental means.

Further research of fatigue crack growth has shown that there exists three important factors not considered in the Paris model. First was the effect of load ratio, $R$, on crack growth $(R=$ minimum cyclic load $/$ maximum cyclic load). Second was the instability of crack growth observed when the stress intensity factor range approached the material's fracture toughness index, $K_{I C}$. Third was the presence of a stress intensity threshold factor, $\Delta K_{t h}$. The stress intensity threshold factor is the highest stress intensity factor in which no crack growth would occur. The Collipriest crack growth model [12] accounts for these effects where

$$
\frac{d a}{d N}=C\left(K_{I C} \Delta K_{t h}\right)^{\frac{n}{2}} \cdot \exp \left\{\ln \left(\frac{K_{I C}}{\Delta K_{t h}}\right)^{\frac{n}{2}} \cdot \tanh ^{-1}\left[\frac{\ln \left(\frac{\Delta K^{2}}{(1-R) K_{I C} \Delta K_{t h}}\right)}{\ln \left(\frac{(1-R) K_{I C}}{\Delta K_{t h}}\right)}\right]\right\}
$$

In addressing applications to gears, Inoue, et al. [7] describes fatigue crack growth of gear bending fatigue tests. Here, crack growth equations were derived as a function of crack depth through a gear tooth. The expression derived for crack growth rate $d a / d n$, as a function of stress intensity range, $\Delta K$, was

$$
\frac{d a}{d N}=\left\{\begin{array}{lr}
\frac{\lambda}{\left(1-\alpha^{\eta}\right)}\left(\Delta K^{\eta}-\Delta K_{t h}^{\eta}\right) & \text { for } \Delta K_{t h} \leq \Delta K \leq \Delta K_{C} \\
\frac{\lambda}{\left(1-\alpha^{\eta}\right)} \frac{\Delta K^{\eta} K_{I C} \eta}{\left(K_{I C}^{\eta}-\Delta K^{\eta}\right)} & \text { for } \Delta K_{C}<\Delta K<\Delta K_{I C}
\end{array}\right.
$$

where the parameters $K_{I C}, \alpha, \Delta K_{C}, \Delta K_{t h}, \eta$, and $\lambda$ were all estimated as a function of tooth hardness [7]. 
Crack Propagation Simulation: The analysis of the current study used the FRANC (FRacture ANalysis Code) computer program described by Wawrzynek [13]. FRANC is a general purpose finite element code for the static analysis of cracked structures. FRANC is designed for two-dimensional problems and is capable of analyzing plane strain, plane stress, or axi-symmetric problems.

Among the variety of capabilities, a unique feature of FRANC is the ability to model a crack in a structure. FRANC uses a method called "delete and fill" to accomplish this. To illustrate, the user would first define an initial crack by identifying the node of the crack mouth and coordinates of the crack tip. FRANC will then delete the elements in the vicinity of the crack tip. FRANC will next insert a rosette of quarter-point, six-node triangular elements around the crack tip to model the inverse square-root stress singularity [14,15]. Finally, FRANC will fill the remaining area between the rosette and original mesh with conventional six-node triangular elements. The user can then run the finite element equation solver to determine nodal displacements, forces, stresses, and strains.

A further unique feature of FRANC is the automatic crack propagation capability. After an initial crack is inserted in a mesh, FRANC models a propagated crack as a number of straight line segments. For each segment, FRANC models the crack tip using a rosette of quarter-point elements. FRANC then solves the finite element equations, calculates the stress intensity factors, and calculates the crack propagation angle. After the crack propagation angle is determined, FRANC then places the new crack tip at the calculated angle and at a user-defined crack increment length. The model is then re-meshed using the "delete and fill" method described above. The procedure is repeated a specific number of times as specified by the user. In the current study, the stress intensity factors were determined from the calculated nodal displacements using the displacement correlation method [16]. The method of Erdogan and Sih [17] was used in the current study to determine the crack propagation angle.

Once the stress intensity factors are determined for each segment, the predicted number of crack propagation cycles can be estimated using the fatigue crack growth models. Regardless of the model used, the crack growth rates, dald $N$, were of the form

$$
\frac{d a}{d N}=g(\Delta K)
$$

where $g(\Delta K)$ is given by Eq. (1) for the Paris relationship, Eq. (2) for the Collipriest relationship, or Eq. (3) for Inoue's method. The predicted number of crack propagation cycles for the $i_{t h}$ crack segment, $N_{i}$, was estimated by

$$
N_{i}=\frac{a_{i}-a_{i-1}}{g\left(\Delta K_{i}\right)}+N_{i-1}
$$

where $a_{i}$ was the crack length of the $i_{t h}$ segment, $a_{i-1}$ was the crack length of the $(i-1)_{t h}$ segment, $N_{i-1}$ was the number of cycles of the $(i-1)_{t h}$ segment, and $g\left(\Delta K_{i}\right)$ was the average crack growth rate of the $i_{t h}$ and $(i-1)_{t h}$ segments. Note that $a_{1}$ was the initial crack length, $N_{1}=0$, and $i$ varied from 2 to the total number of segments.

Gear Finite Element Modeling: Basic gear tooth geometry data was input to a tooth coordinate generation computer program. The tooth coordinate generator program used the method of Hefeng, et al. [18] to determine the tooth coordinates. The output was tooth coordinate and rim coordinate data which defined a single-tooth sector of a gear. This output was used by a commercial available pre- and post-processing finite element analysis software package [19]. This package created the finite element mesh of the complete gear. FRANC then used this mesh and performed crack propagation simulations.

Figure 1 shows a sample finite element mesh of an uncracked gear. The tooth geometry used modeled that of the test gears of the NASA Lewis Spur Gear Fatigue Rig (described in the following section). The analysis used 8-node, plane stress, quadrilateral finite elements. The mesh was refined in the region of the loaded tooth for improved accuracy. The model of Fig. 1 had 2353 elements and 7295 nodes. Material properties used were that of 
AISI 9310 steel. The tooth load was placed at the highest point of single tooth contact. For boundary conditions, four hub nodes were fixed. In addition, gears with various rim thicknesses were modeled. The parameter describing the rim thickness was the backup ratio, $m_{B}$, where

$$
m_{B}=\frac{b}{h}
$$

where $b$ was the rim thickness, and $h$ was the tooth whole depth. Gears with various backup ratios were modeled by incorporating slots in the model. All cases used the same finite element mesh for the loaded tooth.

Test Facility: Crack propagation experiments were performed in the NASA Lewis Spur Gear Fatigue Rig (Fig. 2). The test stand operated on a torque-regenerative principle in which torque was circulated in a loop of test gears and slave gears. Oil pressure was supplied to load vanes in one slave gear which displaced the gear with respect to its shaft. This produced a torque on the test gears, slave gears, and connecting shafts proportional to the amount of applied oil pressure. A $19 \mathrm{~kW}(25-\mathrm{hp})$, variable-speed motor provided speed to the drive shaft using a belt and pulley. The lubricant used for the gears, bearings, and loading system was a synthetic paraffinic oil. The test gear lubricant was filtered through a 5-micron fiberglass filter.

Test Gears: The test gears were 28-tooth, 8 -pitch, $20^{\circ}$ pressure angle external spur gears with a face width of $6.35 \mathrm{~mm}(0.25 \mathrm{in}$.). The teeth had involute profiles with linear tip relief starting at the highest point of single tooth contact and ending at the tooth tip at an amount of $0.013 \mathrm{~mm}(0.0005 \mathrm{in}$.). All test gears used in the experiments were fabricated and machined from a single batch of material. The test gear material was consumable-electrode vacuum-melted AISI 9310 steel. The gears were case-carburized and ground. The teeth were hardened to a case hardness of $R_{c} 61$ and a core hardness of $R_{c} 38$. The effective case depth (depth at a hardness of $R_{c} 50$ ) was $0.81 \mathrm{~mm}(0.032 \mathrm{in}$.). Two different test gear designs were considered. The first was a thick-rimmed gear with a backup ratio of $m_{B}=3.3$ (Fig. 3(a)). The second was a thin-rimmed gear which incorporated slots (Fig. 3(b)). The backup ratio of the thin-rimmed gear was $m_{B}=0.3$.

It was believed that tooth bending fatigue cracks would be difficult to initiate based on the load capacity of the test rig. Due to this, notches were fabricated in the fillet region (loaded side) on one tooth of each of the test gears to promote crack initiation. The notches were fabricated using electrodischarge machining (EDM) with a 0.10-mm (0.004-in.) diameter wire electrode. The nominal notch dimensions were $0.20 \mathrm{~mm}(0.008 \mathrm{in}$.) in length and $0.13 \mathrm{~mm}$ $(0.005 \mathrm{in}$.) in width along the full face width of the tooth. The notches were located at the same location for both test gears. This location was at a radius of $40.49 \mathrm{~mm}$ (1.594 in.) on the fillet, which was the position of the greatest tensile stress for the solid gear $\left(m_{B}=3.3\right)$. The notches produced a stress concentration factor of approximately three as determined using a finite element analysis.

Instrumentation: The standard test rig instrumentation monitored test gear speed, oil load pressure, test gear and slave gear oil pressure, and oil temperatures. Also, overall test stand vibration was monitored using an accelerometer mounted on the top housing. In addition to the standard facility vibration sensor, an advanced vibration processing diagnostic system was installed in the test stand to help assist in crack detection. Crack propagation gages were used in the experiments to determine fatigue crack growth. Special gages were fabricated for installation in the tooth fillet region of the test gears. The gages had ten circular strands with an inner radius of $1.52 \mathrm{~mm}(0.060 \mathrm{in}$.) and an outer radius of $3.05 \mathrm{~mm}(0.120 \mathrm{in}$.) (Fig. 4). The strands were designed to break as the crack propagated though them, which in turn, increased the electrical resistance of the gage (Fig. 4(a)). Figure 4(b) shows the installation of a gage in the fillet region of a notched tooth. A gage was installed on each side of the tooth flank for each gear instrumented with crack gages. The electrical resistance of the crack gages were monitored along with the load cycle count to estimate cycles as a function of crack length. The information from the rotating crack gages was transferred through brush-type slip rings. Also, an infrared tach sensor was used to measure number of load cycles.

Measured Gear Fatigue Crack Growth: The thin-rimmed gear was used in test 1 . The test was run at $89 \mathrm{~N} \cdot \mathrm{m}$ (786 in.. $\mathrm{lb}$ ) torque and $10,000 \mathrm{rpm}$ speed for $6.5 \mathrm{hr}$, at which time rim fracture occurred. Figure 5 plots the 
number of load cycles as a function of the measured crack length. The crack gage results indicated the crack growth was non-uniform throughout the tooth face width. A crack started on the rear flank of the tooth at the tip of the notch and reached an initial size of $0.46 \mathrm{~mm}(0.018 \mathrm{in}$.) at 1,060,000 cycles. The crack continued to propagate through the rear flank but did not reach the front flank until approximately $2,680,000$ cycles. At $2,910,000$ cycles, the crack reached a size of $0.64 \mathrm{~mm}(0.025 \mathrm{in}$.) on the front flank, but completed propagated through the rear gage by this time. Even though the crack initiation time was not uniform throughout the tooth face width, the crack propagation rate was uniform. This was indicated by the similarity in slopes of the curves in Fig. 5 for gages 1 and 2.

The thick-rimmed gear was used in test 2 . This gear was run at $136 \mathrm{~N} \cdot \mathrm{m}(1200 \mathrm{in} . \mathrm{lb})$ torque and $10,000 \mathrm{rpm}$ speed for 15 minutes, at which time tooth fracture occurred. Figure 6 gives the processed crack propagation results for test 2 . Note that the crack initiation and crack propagation was fairly uniform throughout the tooth face width for this test.

Comparison of Predicted and Measured Crack Growth: The FRANC computer program was used to simulate crack propagation and calculate mode I stress intensity factors as a function of crack length. The predicted stress intensity factors were then used with three different fatigue crack growth models (Paris, Collipriest, and Inoue) to estimate crack propagation life.

A comparison of predicted crack propagation cycles using the Paris, Collipriest, and Inoue methods is shown in Fig. 7. For this, the thin-rimmed model $\left(m_{B}=0.3\right)$ was used to simulate the test gear of Fig. 3(b). An initial crack of $0.64 \mathrm{~mm}(0.025 \mathrm{in}$.) was placed in the tooth fillet at the location of the maximum tensile stress. Crack propagation was then simulated and the mode I stress intensity factor as a function of crack length is given in Fig. 7(a). From this, six different fatigue growth cases were considered. The first four cases used the Paris equation and material constants of AISI 9310 specimens from experiments of $\mathrm{Au}$ and $\mathrm{Ke}$ [20]. The fifth case used the Collipriest equation and AISI 9310 material constants from Forman and $\mathrm{Hu}$ [21]. The load ratio used was $R=-2.6$ as determined from the finite element analysis. The sixth case used Inoue's method and the material constants of the SCM415 material (SCM415 is a high-strength Japanese steel, similar in properties to AISI 9310). The predicted number of cycles per crack length varied significantly among the cases studied (Fig. 7(b)). Note that the cycles were defined as the number of crack propagation cycles after an initial crack of $0.64 \mathrm{~mm}(0.025 \mathrm{in}$.).

Predicted crack growth for the $m_{B}=0.3$ and 3.3 gears were compared to the measured crack growth from the experiments. Again, the six different prediction schemes as mentioned above were used. The predicted number of crack propagation cycles using the sixth schemes were, on the most part, extremely low compared to the measured number of cycles from the experiments. To account for this, the concept of fatigue crack closure was investigated. Elber [22] performed crack experiments on aluminum alloys and deduced that residual compressive stresses existed near the crack tip region due to plastic deformation. These residual stresses reduced the effective stress intensity factor range (and thus, increased crack propagation life) and provided a better fit to experimental data than other empirical expressions. Elber proposed an effective stress intensity range ratio, $U$, such that

$$
\Delta K_{e f f}=U(\Delta K)
$$

where $\Delta K_{\text {eff }}$ was the effective stress intensity factor range. Elber then used the effective stress intensity factor range in the Paris fatigue crack growth model. In addition, Elber defined $U$ through experimental studies as a linear function of the load ratio, $R$.

The concept of fatigue crack closure was applied to the current gear crack experiments and predictions. A study was then conducted to estimate the effective stress intensity factor range ratio for the gear crack experiments. The predicted number of crack propagation cycles using the previously mentions six schemes were plotted versus crack length at a variety of arbitrarily chosen $U$ ratios. For the Paris equation and material constants $n=2.954$ and 
$C=8.433 \times 10^{-9} \mathrm{~mm} / \mathrm{cyc} /(\mathrm{MPa} \sqrt{\mathrm{m}})^{\mathrm{n}}$, good correlation between predicted crack cycles and the experiments occurred when: 1) $U=0.4$ for $R=-2.6$, and 2) $U=0.8$ for $R=-0.1$. Assuming a linear relation between $U$ and $R$ produced

$$
U=0.82+0.16(R)
$$

Figure 8 shows a sample comparison of predicted and measured crack growth when the fatigue crack closure concept was used. The cycles were defined as the number of crack propagation cycles after an initial crack of $0.64 \mathrm{~mm}(0.025 \mathrm{in})$. It should be noted that good correlation was also achieved when the Collipriest equation was used with certain $U$ values. This produced a relationship similar to Eq. 8 but with different coefficients [10].

Figure 9 displays the effect of rim thickness on predicted mode I stress intensity factors and predicted crack propagation cycles. The stress intensity factors were determined from FRANC using the appropriate finite element models. The Paris equation was used along with the effective stress intensity range ratios of Eq. 8 . The initial cracks of the various models were placed at the location of the maximum tensile stress in the tooth fillet. The stress intensity factors were lowest for the $m_{B}=0.5$ case. This gave the highest predicted number of cycles for the cases studies. The cycles all were defined as the number of crack propagation cycles after an initial crack of $0.28 \mathrm{~mm}(0.011 \mathrm{in})$. The stress intensity factors were highest for the $m_{B}=0.3$ case. However, the predicted life for this was somewhere between the case of $m_{B}=0.5$ and 1.0 due to the fatigue crack closure effect. The cases of $m_{B}=3.3$ and 1.0 gave nearly the same predicted life.

Conclusions: Analytical and experimental studies were performed to investigate the effect of gear rim thickness on crack propagation life. The following conclusions were made: 1) Good correlation between predicted and measured gear crack growth was achieved when the predictions used the Paris crack growth equation and the concept of fatigue crack closure. 2) For thin rims, a decrease in rim thickness caused an increase in both the stress intensity factor and the compressive cyclic stress in the gear tooth fillet region. The increase in stress intensity factor promoted crack growth while the increase in cyclic compressive stress tended to retard crack growth and increase the number of propagation cycles to failure.

Acknowledgment: The authors wish to thank Dr. Paul A. Wawrzynek of Fracture Analysis Consultants, Inc., for fruitful discussions and for providing the FRANC program.

\section{References:}

1. "Fundamental Rating Factors and Calculation Methods for Involute Spur and Helical Gear Teeth", ANSI AGMA 2001-B88, American Gear Manufacturers Association, Alexandria, VA, 1990.

2. Drago, R.J., and Lutthans, R.V., "Combined Effects of Rim Thickness and Pitch Diameter on Spur Gear Tooth Stresses", Journal of the American Helicopter Society, Vol. 28, Jul., pp 13-19, 1983.

3. Ahmad, J., and Loo, F.T., "On the Use of Strain Energy Density Fracture Criterion in the Design of Gears Using Finite Element Method", ASME Paper No. 77-DET-158, presented at the Design Technical Conference, Chicago, IL, Jun., 1977.

4. Honda, H., and Conway, J.C., "An Analysis by Finite Element Techniques of the Effects of a Crack in the Gear Tooth Fillet and its Applicability to Evaluating Strength of the Flawed Gears", Bulletin of the JSME, Vol. 22, No. 174, Dec., pp. 1848-1855, 1979.

5. Flasker, J., and Jezernik, A., "The Comparative Analysis of Crack Propagation in the Gear Tooth", Proceedings of the International Conference of Application of Fracture Mechanics to Materials and Structures, Freiburg, West Germany, Jun., pp. 971-982, 1983.

6. Kato, M., Inoue, K., Deng, G., and Jeong, B.S., "Strength Evaluation of Carburized Gear Teeth Based on Fracture Mechanics", Proceedings of the KSME/JSME Joint Conference "Fracture and Strength '90", Seoul, Korea, pp. 248-253, 1990. 
7. Inoue, K., Kato, M., Deng, G., and Takatsu, N., "Fracture Mechanics Based Evaluation of Strength of Carburized Gear Teeth", Proceedings of the JSME International Conference on Motion and Power Transmissions, Hiroshima, Japan, Nov., pp. 801-806, 1991.

8. Daniewicz, S.R., Collins, J.A., and Houser, D.R., "The Stress Intensity Factor and Stiffness for a Cracked Spur Gear Tooth", Journal of Mechanical Design, Vol. 116, No. 3, Sep., 1994.

9. Flasker, J., and Pehan, S., "Crack Propagation in Tooth Root With Variable Loading", Communications in Numerical Methods in Engineering, Vol. 9, No. 2, Feb., pp. 103-110, 1993.

10. Lewicki, D.G., "Crack Propagation Studies to Determine Benign or Catastrophic Failure Modes for Aerospace Thin-Rim Gears", Ph.D. Dissertation, Case Western Reserve University, May 1995.

11. Paris, P.C., and Erdogen, F., "A Critical Analysis of Crack Propagation Laws", Journal of Basic Engineering, Vol. 85, pp. 528-534, 1963.

12. Collipriest, J.E., "An Experimentalist's View of the Surface Flaw Problem", The Surface Crack: Physical Problems and Computational Solutions, American Society of Mechanical Engineers, pp. 43-61, 1972.

13. Wawrzynek, P.A., "Discrete Modeling of Crack Propagation: Theoretical Aspects and Implementation Issues in Two and Three Dimensions", Ph.D. Dissertation, Cornell University, 1991.

14. Henshell, R.D., and Shaw, K.G., "Crack Tip Finite Elements Are Unnecessary", International Journal for Numerical Methods in Engineering, Vol. 9, pp. 495-507, 1975.

15. Barsoum, R.S., "On the Use of Isoparametric Finite Elements in Linear Fracture Mechanics", International Journal for Numerical Methods in Engineering, Vol. 10, No. 1, pp. 25-37, 1976.

16. Tracey, D.M., "Discussion of 'On the Use of Isoparametric Finite Elements in Linear Fracture Mechanics' by R.S. Barsoum", International Journal for Numerical Methods in Engineering, Vol. 11, pp. 401-402, 1977.

17. Erdogan, F., and Sih, G.C., 1963, "On the Crack Extension in Plates Under Plane Loading and Transverse Shear", Journal of Basic Engineering, Vol: 85, pp. 519-527, 1963.

18. Hefeng, B., Savage, M., and Knorr, R.J., "Computer Modeling of Rack-Generated Spur Gears", Mechanism and Machine Theory, Vol. 20, No. 4, pp. 351-360, 1985.

19. P3/PATRAN User Manual, PDA Engineering, Costa Mesa, CA, 1993.

20. Au, J.J., and Ke, J.S., "Correlation Between Fatigue Crack Growth Rate and Fatigue Striation Spacing in AISI 9310 Steel", Fractography and Materials Science, ASTM STP 733, pp. 202-221, 1981.

21. Forman, R.G., and Hu, T., 1984, "Application of Fracture Mechanics on the Space Shuttle", Damage Tolerance of Metallic Structures, ASTM STP 842, pp. 108-133, 1984.

22. Elber, W., "The Significance of Fatigue Crack Closure", Damage Tolerance in Aircraft Structures, ASTM STP 486, pp. 230-242, 1971. 


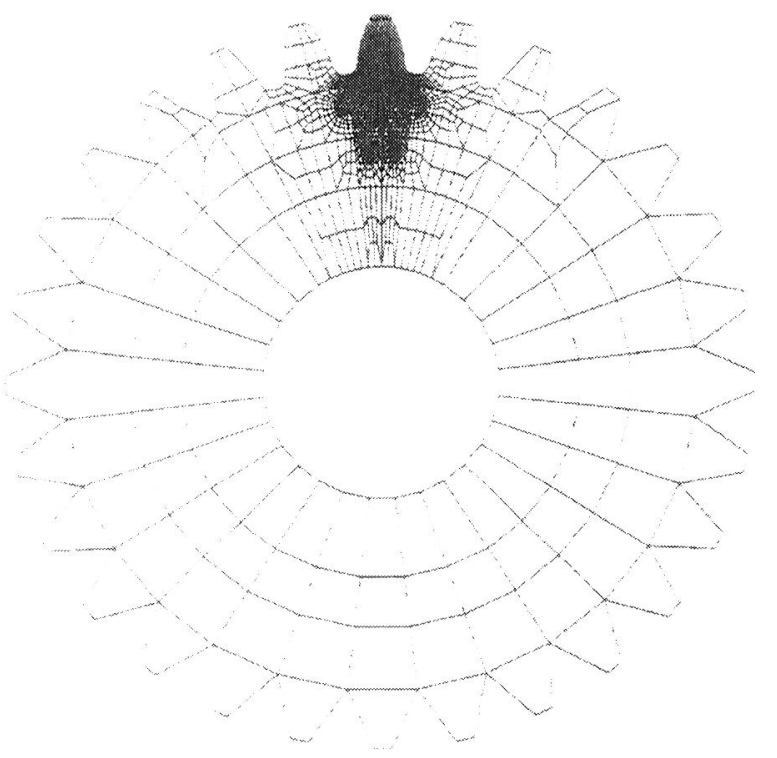

Figure 1.-Finite element model of gears used in crack propagation studies, solid model, $m_{B}=3.3$.

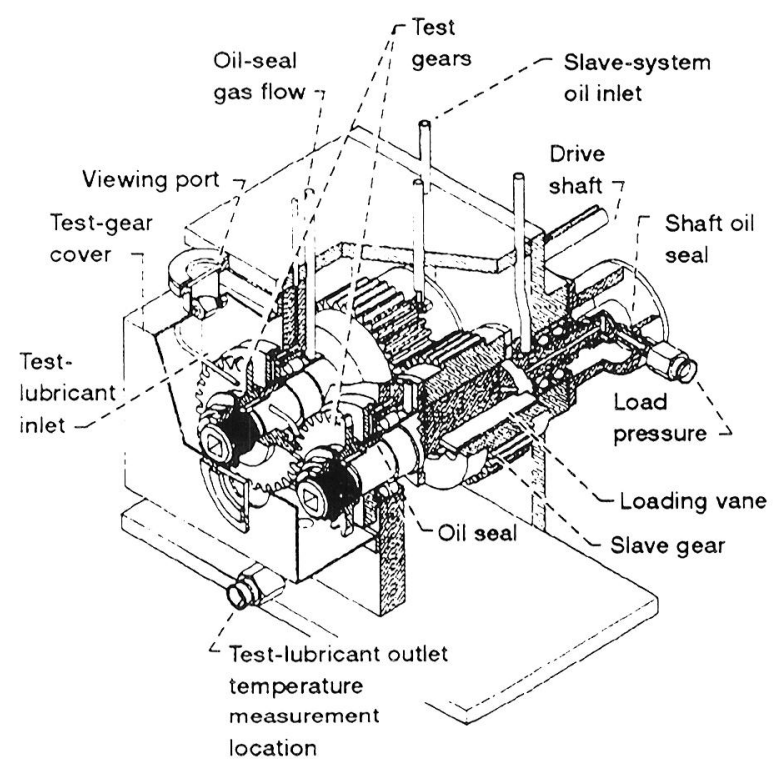

Figure 2.-NASA Lewis Spur Gear Fatigue Rig.

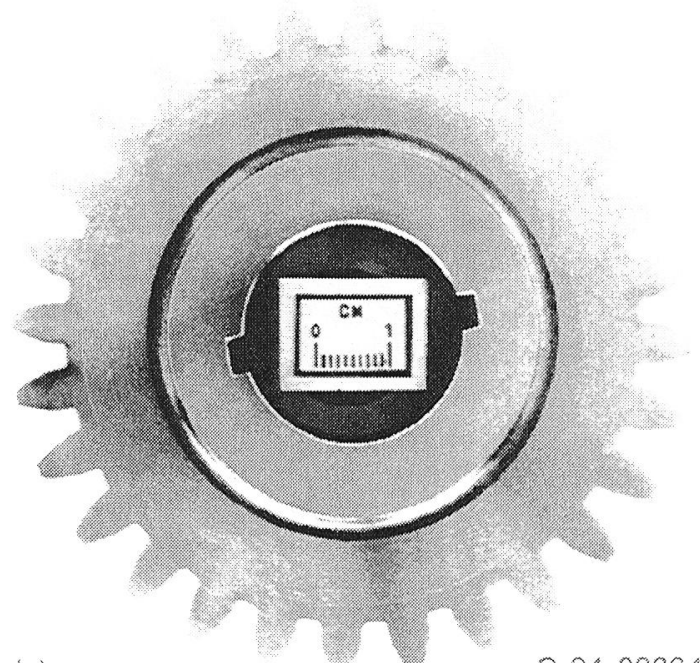

(a)

$0-94-02304$

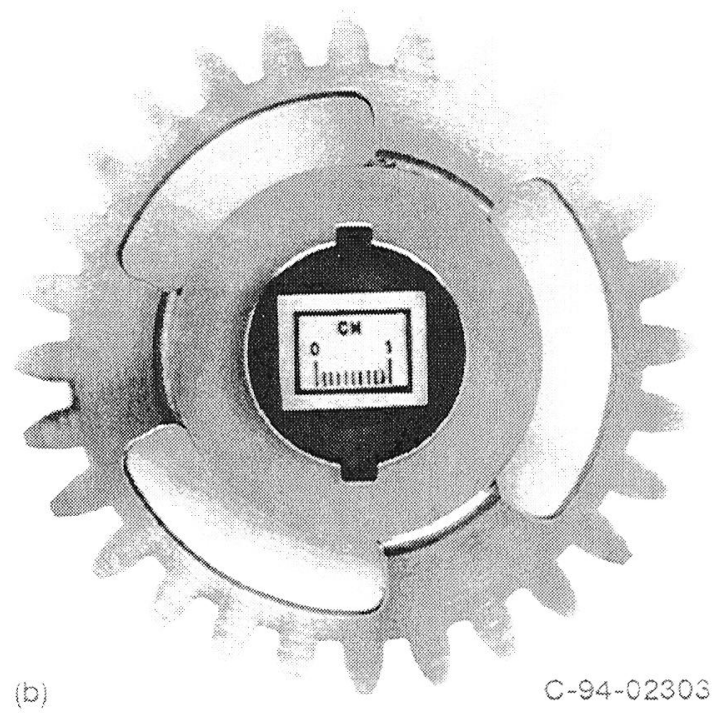

Figure 3.-Test gears used to determine effect of rim thickness on crack propagation. (a) $m_{B}=3.3$. (b) $m_{B}=0.3$. 

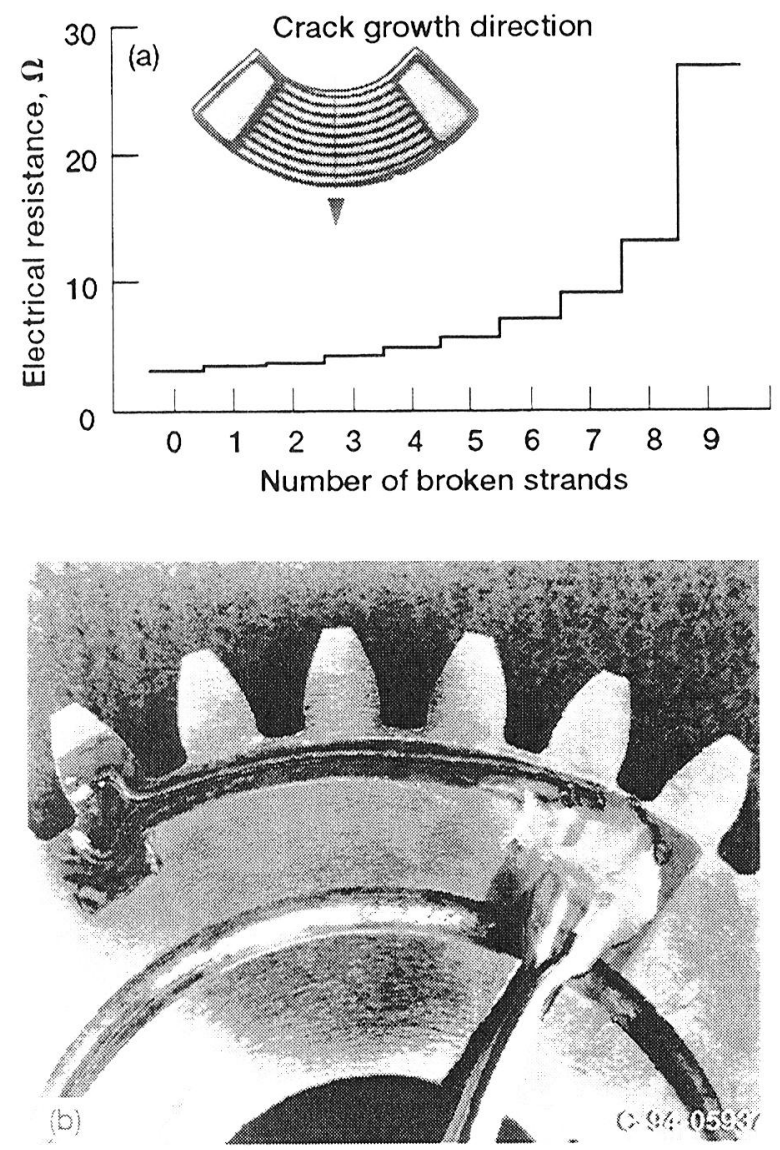

Figure 4.-Specialized crack propagation gages for gear tooth crack growth measurements. (a) Increase in gage electrical resistance as the number of broken strands increase. (b) Installation of crack propagation gage on test gear.

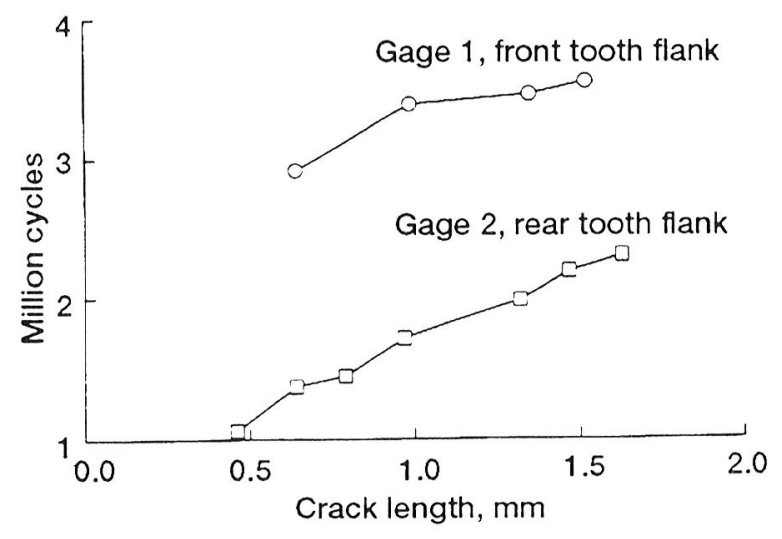

Figure 5.-Crack propagation fatigue growth for test $1, m_{B}=0.3$.

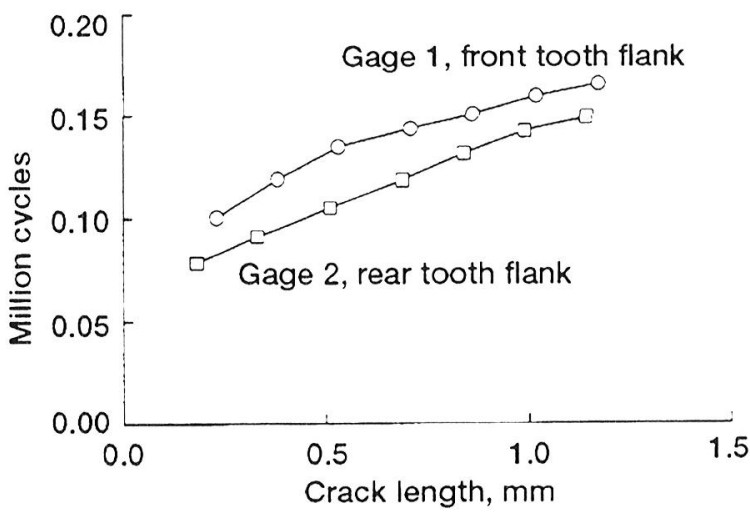

Figure 6.-Crack propagation fatigue growth for test $2, m_{B}=3.3$. 

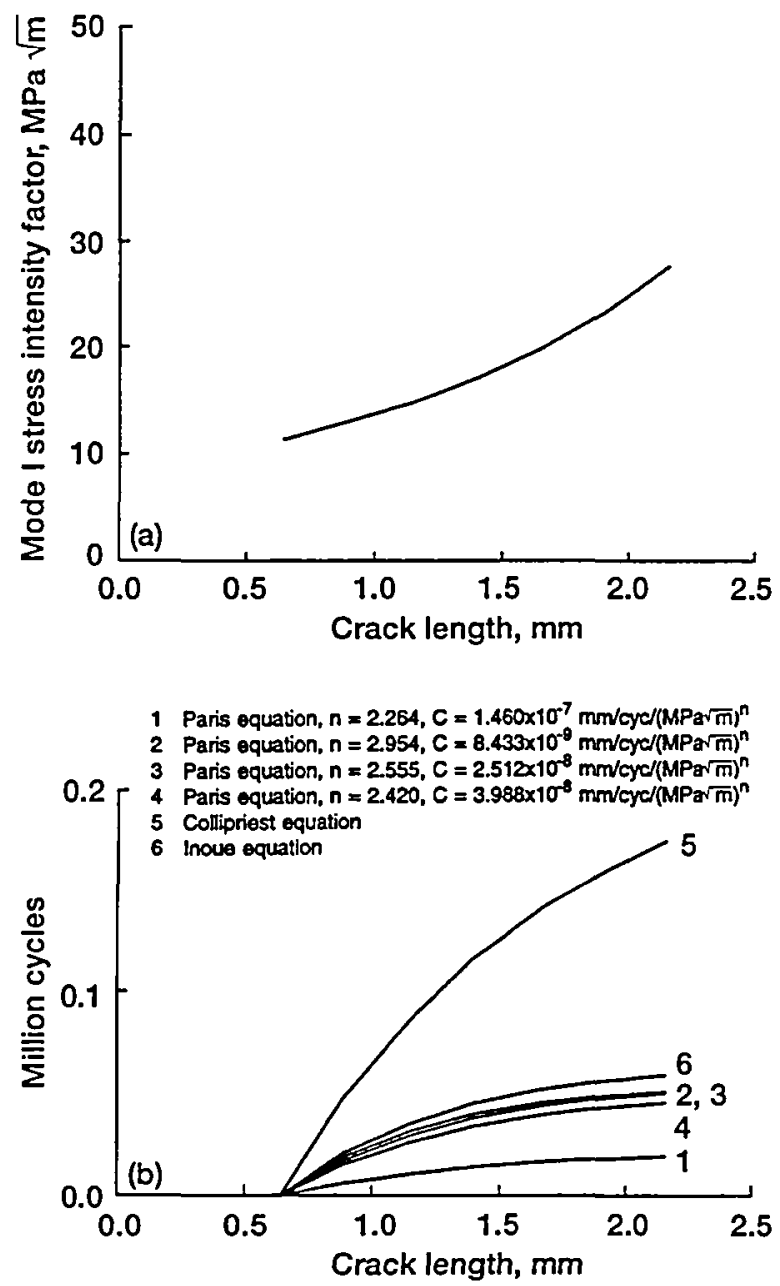

Figure 7.-Comparison of predicted crack propagation cycles using Paris equation, Collipriest equation, and Inoue equation. Model for $\mathrm{m}_{\mathrm{B}}=\mathbf{0 . 3}$. (a) Mode I stress intensity factor. (b) Life comparison.

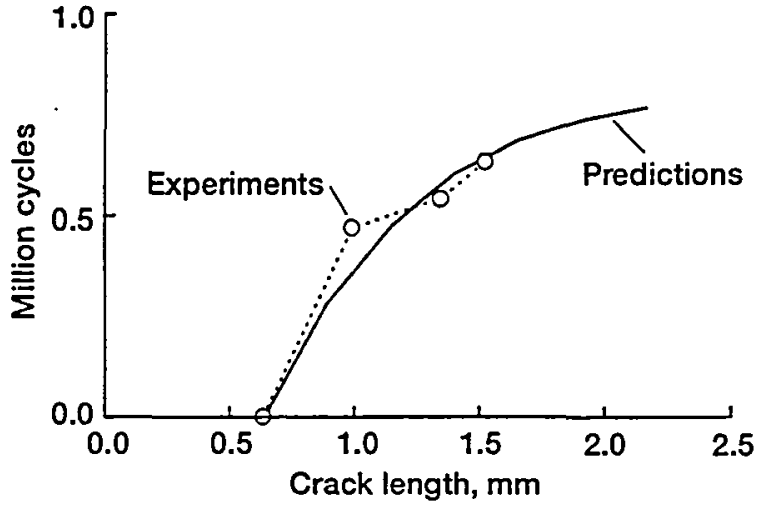

Figure 8.-Comparison of predicted crack propagation cycles to experiments. Paris fatigue crack growth model, $\mathrm{n}=2.954, \mathrm{C}=8.433 \times 10^{-9} \mathrm{~mm} / \mathrm{cyc} /$ $(\mathrm{MPa} \sqrt{\mathrm{m}})^{\mathrm{n}}, \mathrm{R}=-\mathbf{2 . 6}, \mathrm{U}=0.4$, used for predictions. Test 1, gage 1, front flank, for experiments.
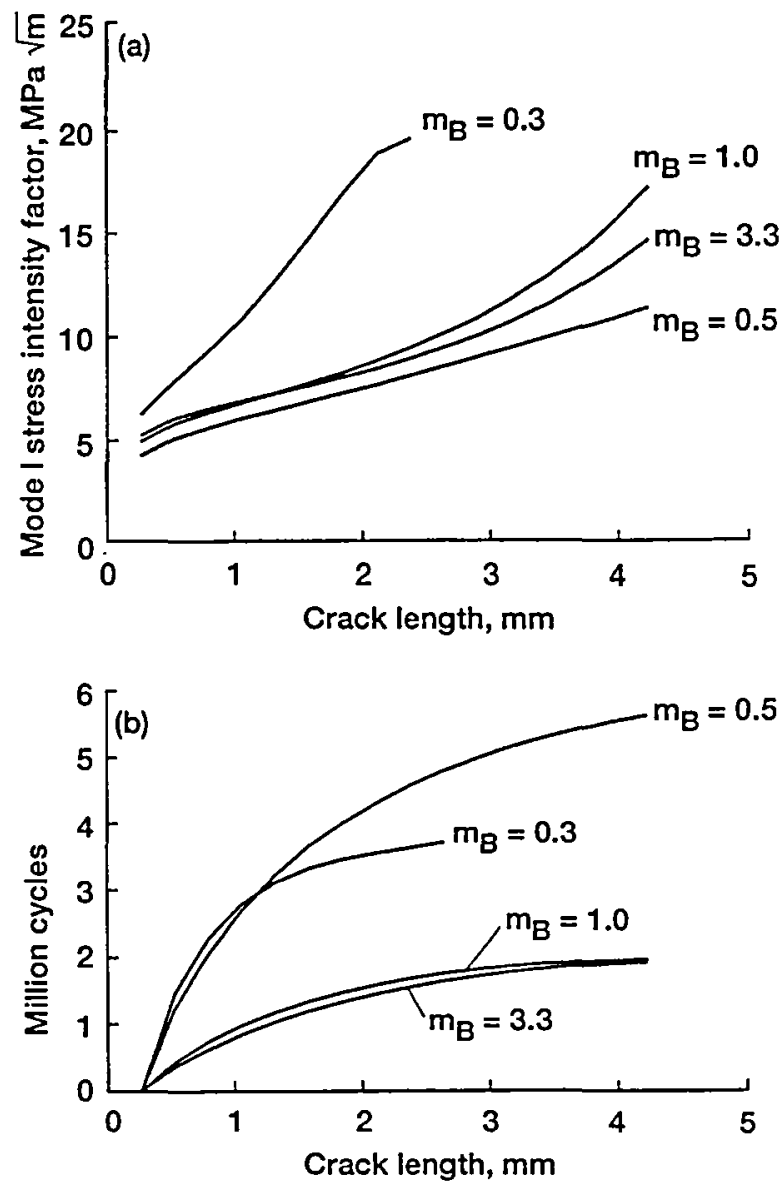

Figure 9.-Effect of backup ratio on stress intensity factors and crack propagation cycles. (a) Mode I stress intensity factors. (b) Crack propagation cycles, Paris fatigue crack growth model, $n=2.954$, $\mathrm{C}=8.433 \times 10^{-9} \mathrm{~mm} / \mathrm{cyc} /(\mathrm{MPa} \sqrt{\mathrm{m}})^{\mathrm{n}}, \mathrm{U}=0.82+$ $0.16 \mathrm{R}$. 
Public teporting burden for this collection of information is estimated to average 1 hour per response, including the time for reviewing instructions, searching existing data sources, gathering and maintaining the data needed, and completing and reviewing the collection of information. Send comments rogarding this burden estimate or any of er aspect

Davis Highway, Suite 1204, Arlington. VA 22202-4302, and to the Office of Management and Budget, Paperwork Reduction Proped (0704-0188). Washington, DC 20503.

\begin{tabular}{|l|l|l} 
1. AGENCY USE ONLY (Leave blank) & $\begin{array}{c}\text { 2. REPORT DATE } \\
\text { January } 1996\end{array}$ & $\begin{array}{r}\text { 3. REPORT TYPE AND DATES COVERED } \\
\text { Technical Memorandum }\end{array}$
\end{tabular}

\section{TITLE AND SUBTITLE}

Gear Crack Propagation Investigations

\section{FUNDING NUMBERS}

WU-505-62-36

1L162211A47A

David G. Lewicki and Roberto Ballarini

7. PERFORMING ORGANIZATION NAME(S) AND ADDRESS(ES)

NASA Lewis Research Center

Cleveland, Ohio 44135-3191

and

Vehicle Propulsion Directorate

U.S. Army Research Laboratory

Cleveland, Ohio 44135-3191

9. SPONSORINGMONITORING AGENCY NAME(S) AND ADDRESS(ES)

National Aeronautics and Space Administration

Washington, D.C. 20546-0001

and

U.S. Amny Research Laboratory

Adelphi, Maryland 20783-1145
8. PERFORMING ORGANIZATION REPORT NUMBER

E-10080

10. SPONSORINGMONITORING AGENCY REPORT NUMBER

NASA TM-107147

ARL-TR-957

11. SUPPLEMENTARY NOTES

Prepared for An Integrated Monitoring, Diagnostics, \& Failure Prevention Technology Showcase, Mobile, Alabama, April 22-26, 1996. David G. Lewicki, Vehicle Propulsion Directorate, U.S. Army Research Laboratory, NASA Lewis Research Center; and Roberto Ballarini, Case Westem Reserve, Department of Civil Engineering and Mechanical \& Aerospace Engineering, Cleveland, Ohio 44106. Responsible person, David G. Lewicki, organization code 2730, (216) 433-3970.

12a. DISTRIBUTIONAVAILABILTTY STATEMENT

12b. DISTRIBUTION CODE

Unclassified - Unlimited

Subject Category 37

This publication is available from the NASA Center for Aerospace Information, (301) 621-0390.

13. ABSTRACT (Maximum 200 words)

Analytical and experimental studies were performed to investigate the effect of gear rim thickness on crack propagation life. The FRANC (FRacture ANalysis Code) computer program was used to simulate crack propagation. The FRANC program used principles of linear elastic fracture mechanics, finite element modeling, and a unique re-meshing scheme to determine crack tip stress distributions, estimate stress intensity factors, and model crack propagation. Various fatigue crack growth models were used to estimate crack propagation life based on the calculated stress intensity factors. Experimental tests were performed in a gear fatigue rig to validate predicted crack propagation results. Test gears were installed with special crack propagation gages in the tooth fillet region to measure bending fatigue crack growth. Good correlation between predicted and measured crack growth was achieved when the fatigue crack closure concept was introduced into the analysis. As the gear rim thickness decreased, the compressive cyclic stress in the gear tooth fillet region increased. This retarded crack growth and increased the number of crack propagation cycles to failure.

14. SUBJECT TERMS

Crack propagation; Finite element modeling; Fracture mechanics; Gears; Rims 12 16. PRICE CODE $\mathrm{A} 03$

17. SECURITY CLASSIFICATION OF REPORT

Unclassified
18. SECURITY CLASSIFICATION OF THIS PAGE Unclassified
19. SECURITY CLASSIFICATION OF ABSTRACT Unclassified 
National Aeronautics and

Space Administration

\section{Lewis Research Center}

21000 Brookpark Rd.

Cleveland, $\mathrm{OH}$ 44135-3191

Ofícial Business

Penalty for Private Use $\$ 300$

POSTMASTER: If Undeliverable - Do Not Retu

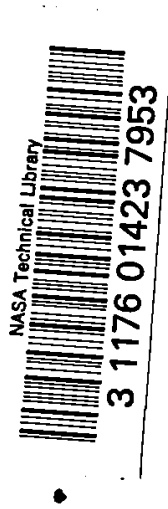

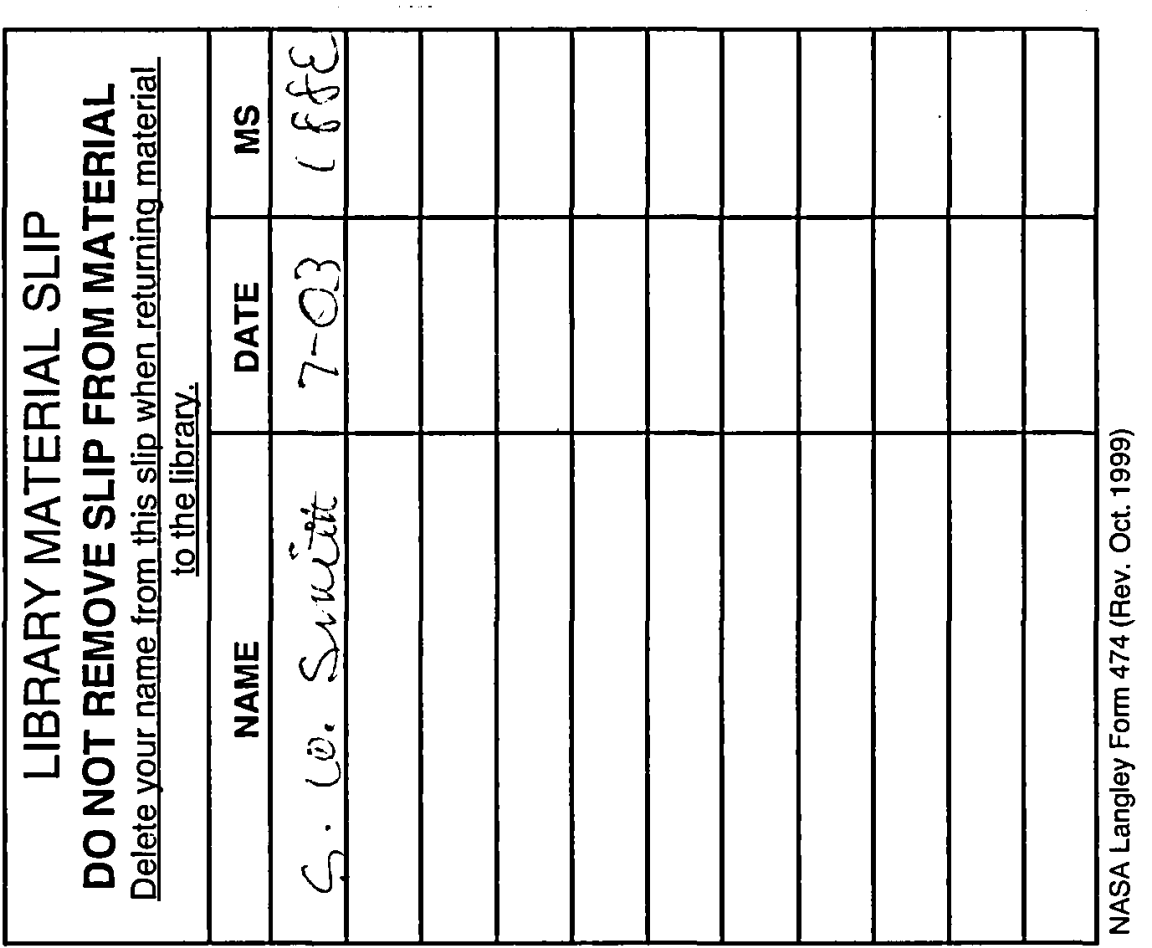

